Jilid 7 Nomor 2 Juli 2021

Hal 159--168

\title{
PENGARUH PERSEPSI, MOTIVASI, DAN PENGETAHUAN MASYARAKAT DALAM MEMILIH PRODUK BANK SYARIAH DI BANJARMASIN
}

\begin{abstract}
Abul Hasan Asy'ari
Abstrak: Bank syariah di Indonesia memiliki prospek yang sangat besar mengingat penduduk muslim merupakan yang terbesar di Indonesia. namun ironisnya nasabah Bank Syariah masih kecil bila dibandingkan dengan bank konvensional. Hal ini disebabkan oleh berbagai faktor anatara lain persepsi masyarakat yang memandang bank syariah yang masih kurang baik dibanding bank konvensional, kurangnya motivasi masyarakat untuk menjadi nasabah serta pengetahuan masarakat yang masih minim tentang produk dan layanan yg dimiliki Bank Syariah. Penelitian ini bertujuan untuk mengetahui pengaruh variabel Persepsi, Motivasi, dan Pengetahuan Masyarakat terhadap pemilihan produk Bank Syariah di Banjarmasin. Penelitian ini merupakan penelitian korelasional dengan populasi adalah seluruh nasabah bank syariah di Banjarmasin. Sampel dalam penelitian ini adalah 100 responden dimana penarikan sampel menggunakan teknik accidental sampling. Analisis data menggunakan analisis regresi linear berganda. Hasil penelitian menunjukkan bahwa variabel Persepsi, Motivasi dan Pengetahuan berpengaruh signifikan terhadap keputusan masyarakat memilih produk bank syariah. Disarankan kepada bank syariah untuk terus berupaya meningkatkan persepsi, motivasi dan pengetahuan masyarakat terhadap produk dan layanannya. Bagi peneliti selanjutnya hendaknya memperbanyak variabel penelitian mengingat ketiga variabel tersebut memiliki hubungan yang tidak terlalu kuat dalam menjelaskan faktor yang mempengaruhi masyarakat memilih produk bank syariah.
\end{abstract}

Kata kunci : Persepsi, Motivasi, Pengetahuan, Keputusan Memilih 


\section{Pendahuluan}

Industri perbankan adalah meliputi segala sesuatu yang berkaitan dengan institusi perbankan, mencakup kelembagaan, kegiatan usaha, serta cara dan proses dalam melaksanakan kegiatan usahanya. Industri ini merupakan salah satu industri yang memiliki persaingan yang sangat ketat terutama dalam merebut nasabah, hal ini disebabkan banyaknya perusahaan perbankan yang beroperasi, ditambah lagi semenjak lahirnya bank syariah.

Bank Muamalat Indonesia, adalah bank umum pertama di Indonesia yang menerapkan prinsip Syariah Islam dalam menjalankan operasionalnya. Didirikan pada tahun 1991, yang diprakarsai oleh Majelis Ulama Indonesia (MUI) dan Pemerintah Indonesia. Mulai beroperasi pada tahun 1992. Bank syariah saat ini telah menjadi pesaing aktif yang diperhitungkan oleh bank-bank konvensional karena perkembangan bank syariah yang cukup pesat semenjak lahirnya tahun 1991, Menurut data statistik Perbankan Syariah yang dikeluarkan oleh Otoritas Jasa keuangan (OJK) pada April 2018, terdapat 13 Bank Umum Syariah (BUS), 21 Unit Usaha Syariah (UUS) dan 168 BPRS dengan total aset BUS dan UUS sebesar Rp. 423.944 Miliar. Detail statistik di atas digambarkan dalam tabel di bawah ini.

Tabel 1

Perkembangan Bank Syariah di Indonesia

\begin{tabular}{|l||c|c|l|}
\hline $\begin{array}{l}\text { Kelompok } \\
\text { Bank }\end{array}$ & $\begin{array}{c}\text { Jumlah } \\
\text { Bank }\end{array}$ & Jumlah & $\begin{array}{l}\text { Total } \\
\text { kantor } \\
\text { kantor } \\
\text { (Miliar } \\
\text { Rupiah }\end{array}$ \\
\hline $\begin{array}{l}\text { Bank } \\
\text { Umum } \\
\text { Syariah }\end{array}$ & 13 & 1.822 & 292.289 \\
\hline $\begin{array}{l}\text { Unit Usaha } \\
\text { Syariah }\end{array}$ & 21 & 348 & 131.655 \\
\hline BPRS & 168 & 458 & - \\
\hline
\end{tabular}

\begin{tabular}{|l||c|c|c|}
\hline $\begin{array}{l}\text { Jumlah } \\
\text { Account } \\
\text { (DPK) }\end{array}$ & 8,2 & 10,8 & 12,3 \\
\hline Total & 202 & 2.628 & 423.944 \\
\hline
\end{tabular}

Sumber : Outlook Perbankan Syariah 2018

Dari tabel di atas terlihat sejak berdirinya bank syariah, perkembangan perbankan syariah cukup pesat dimana sekarang sudah berdiri 13 bank umum syariah, 21 unit usaha dan 168 BPRS. Ke depan lembaga perbankan dan keuangan syariah di Indonesia diprediksi akan terus meningkat.

Bank syariah di Indonesia memiliki prospek yang besar mengingat penduduk muslim merupakan yang terbesar di Indonesia yaitu mencapai $87,2 \%$. namun ironisnya sampai dengan tahun 2018 market share bank syariah masih dalam kisaran 5,7\% hal ini menggambarkan betapa kecil market share yang mampu di raih oleh bank-bank syariah. Hal ini disebabkan oleh berbagai faktor anatara lain persepsi masyarakat terhadap bank syariah yang masih kurang baik dibanding bank konvensional, mengingat bank syariah masih dianggap bank yang baru berdiri dimana masih banyak kekurangan baik dari segi kecepatan pelayanan, kelengkapan produk dan teknologi yang dianggap masih kalah jauh dibanding bank konvensional yang sudah lama berdiri. Begitu juga pengetahuan masyarakat terhadap produk dan layanan pendanaan bank syariah masih sangat minim. Karena bank syariah beroperasi berdasarkan prinsif syariah maka produk yang ditawarkan juga menggunakan istilah istilah dalam bahasa arab yang masih kurang familiar bagi masyarakat indonesia, akibatnya hanya sedikit produk yang diketahui dengan baik, hal tersebut mengakibatkan masih terbatasnya akses masyarakat terhadap 
penggunaan produk bank syariah seperti produk simpanan, pendanaan dan fasilitas jasa keuangan lainnnya. Padahal bank syariah memiliki produk yang cukup lengkap tidak kalah dibanding bank konvensional, hanya saja masyarakat belum banyak yang mengetahuinya.

\section{Kajian Literatur}

\section{Keputusan Pembelian ( Keputusan memilih produk bank syariah)}

Keputusan pembelian menurut Schiffman, Kanuk (2004) adalah pemilihan dari dua atau lebih alternatif pilihan keputusan pembelian, artinya bahwa seseorang dapat membuat keputusan, haruslah tersedia beberapa alternatif pilihan. Keputusan untuk membeli dapat mengarah kepada bagaimana proses dalam pengambilan keputusan tersebut itu dilakukan.

\section{Persepsi}

Menurut Kotler dan Keller (2009:179), persepsi adalah proses di mana kita memilih, mengatur, dan menerjemahkan masukan informasi untuk menciptakan gambaran dunia yang berarti. Menurut Schiffman dan Kanuk (2007), persepsi dapat didefinisikan sebagai proses seorang individu untuk memilih, mengorganisasi, dan menginterpretasi suatu stimulus menjadi gambaran yang bermakna dan berhubungan dengan dunia, atau dengan kata lain dapat dikatakan sebagai "cara kita melihat dunia di sekeliling kita". Menurut Hawkins, Mothersbaugh dan Best (2007), persepsi adalah sebuah proses yang diawali dengan pemaparan konsumen dan perhatian terhadap rangsangan pemasaran dan berakhir dengan penafsiran oleh konsumen.

Hawkins \& Mothersbaugh (2013) menyatakan bahwa Persepsi adalah "suatu proses yang dimulai dari konsumen" paparan dan perhatian pada rangsangan dan tujuan pemasaran dengan interpretasi konsumen" . Berdasarkan Schiffman dan Wisenblit (2015),persepsi akan menciptakan citra konsumen terhadap objek tertentu yang mempengaruhi proses keputusan pembelian konsumen. Citra konsumen adalah "persepsi konsumen dari semua komponen produk, layanan, dan merek dan bagaimana konsumen mengevaluasi kualitas penawaran pemasar" (Schiffman \& Wisenblit, 2015).

\section{Motivasi}

Robbins (2008) mendefinisikan motivasi sebagai proses yang ikut menetukan intensitas, arah, dan ketentuan individu dalam usaha mencapai sasaran. Dalam industri bisnis, motivasi memainkan peran penting dalam proses pembelian konsumen. Motif berawal dari kebutuhan individu dimana ada tekanan kuat untuk mencari kepuasan dan kesenangan (Kotler \& Amstrong, 2011). Setiadi (2013) juga menjelaskan bahwa ada dua jenis motivasi yang dapat mempengaruhi pembelian konsumen keputusan, yang merupakan motivasi rasional (berdasarkan objektivitas dalam menilai produk) dan emosional motivasi (berdasarkan subjektivitas dalam menilai produk). Oleh karena itu, dalam membeli produk tertentu, motivasi rasional dan motivasi emosional mungkin berdampak pada keputusan pembelian konsumen.

\section{Pengetahuan}

Theory of Planned Behavior (TPB) merupakan model yang dapat digunakan untuk menilai suatu perilaku seseorang (Ajzen,2005). Teori ini digunakan untuk mengeksplorasi perilaku yang direncanakan. Di dalam kategori, Ajzen (2005) mencakup tiga faktor, yaitu pribadi,sosial, dan informasi. Dimana faktor informasi adalah pengetahuan, media, dan intervensi.

Pengetahuan bank syariah terkait dengan faktor informasi, yaitu pengetahuan dan mempengaruhi dalam mengendalikan keyakinan. Kendali keyakinan terkait dengan keyakinan bahwa perilaku atau pekerjaan itu dapat dilakukan. Misalnya dengan 
pengetahuan yang dimiliki tentang bank syariah seperti pemahaman, prinsip, produk, dan sebagainya.

Hasil penelitian Ergun \& Djedovic (2010) menyatakan bahwa ada pengaruh positif dan signifikan antara pengetahuan terhadap keputusan masyarakat Bosnia dan Herzegovina dalam memilih Bank Syariah. Penelitian ini juga diperkuat oleh penelitian yang dilakukan oleh Moor \& Sanrego (2011), yang menyatakan bahwa pengetahuan memiliki efek positif pada preferensi orang dalam memilih dan menabung di perbankan syariah di DKI Jakarta.

\section{Penelitian Terdahulu}

Dalam penelitian ini ada beberapa penelitian terdahulu yang digunakan sebagai bahan referensi, yang berhubungan dengan variabel penelitian.

1). Alsadek dkk, (2009), “ Attitudes, Perceptions and Motivations of Libyan Retail Consumers toward Islamic Methods of Finance".

Dalam penelitian ini variabel yang diukur adalah sikap, persepsi dan motivasi masyarakat dalam memilih dan menggunakan produk bank syariah. Metode analisis data yang digunakan adalah analisis faktor dan analisis regresi berganda. Hasil penelitiannya adalah :

1. Berdasarkan uji analisis faktor variabel yang dapat menjelaskan sikap, persepsi dan motivasi masyarakat terhadap metode keuangan Islam hanya pada empat determinan: yaitu, layanan masyarakat, profitabilitas, agama, dan layanan unik.

2. Analisis diskriminan menunjukkan bahwa agama dan pengabdian masyarakat merupakan faktor paling penting yang menentukan potensi penggunaan metode keuangan Islam oleh konsumen ritel di Libya.

2). Faradilla Novita Sari,(2017), "Analisis Faktor Pertimbangan Dan Pengetahuan Masyarakat Surakarta Terhadap Minat Menabung Di Bank Syariah Mandiri”.
Metode analisis data menggunakan statistik deskriptif dan analisis faktor. Hasil analisis menyimpulkan bahwa ada enam faktor yang menjadi pertimbangan konsumen memilih menabung di Bank Syariah Mandiri antara lain: faktor compliance, factor assurance, faktor reliability, faktor tangible, faktor empathy, dan faktor responsiveness. Faktor empathy merupakan faktor yang paling dipertimbangkan konsumen dalam memilih bank syariah.

Pengetahuan konsumen terhadap bank syariah masih terbatas, sebagian besar responden hanya mengetahui tentang bagi hasil dan prosedur pembukaan rekening/ tabungan di Bank Syariah Mandiri. Sedangkan istilah-istilah dan macam produk perbankan syariah seperti mudharabah, musyarakah, murabahah dan ijarah masih belum diketahui dan dimengerti oleh konsumen.

3). Haryadi, (2007), “ Persepsi Masyarakat Terhadap Perbankan Syariah".

Dalam penelitian ini variabel yang diukur yang mempengaruhi persepsi masyarakat terhadap bank syariah adalah variabel pengetahuan, manfaat keuangan, pelayanan, dan lokasi. Metode analisis data menggunakan analisis regresi berganda.

Hasil penelitian adalah :

1. Pengaruh secara simultan menunjukkan bahwa pengetahuan, manfaat keuangan, pelayanan, dan lokasi secara bersamasama berpengaruh signifikan terhadap persepsi masyarakat terhadap bank syariah.

2. Pengaruh secara parsial menunjukkan bahwa semua variabel berpengaruh signifikan terhadap persepsi masyarakat terhadap bank syariah, dimana variabel manfaat keuangan merupakan faktor yang dominan mempengaruhi.

4) . Utamy, Oriesta Dhea Budi, Ratieh Widhiastuti,(2019), "The effect of Sharia bank knowledge, promotion, and facilities on savings decisions at Sharia 
banks with savings interest as mediation variables".

Hasil penelitian menunjukkan bahwa (1) terdapat pengaruh positif dan signifikan pengetahuan bank syariah, promosi, fasilitas, dan niat menabung pada keputusan menabung di Bank Umum Syariah, (2) ada ada pengaruh positif dan signifikan pengetahuan bank syariah, promosi, dan fasilitas untuk niat menabung di Bank Syariah, (3) terdapat pengaruh positif dan signifikan pengetahuan bank syariah, promosi, dan kemudahan dalam pengambilan keputusan untuk menabung di Bank Syariah dengan maksud untuk menabung, (4) variabel minat menabung memiliki pengaruh paling dominan terhadap a keputusan untuk menabung di Bank Syariah.

5) . Gunawan, Steffi (2015), "The Impact of Motivation, Perception and Attitude toward Consumer Purchasing Decision: A Study Case of Surabaya and Jakarta Society on Carl's Junior."

Penelitian ini menguji faktor psikologi dalam mempengaruhi keputusan pembelian. Faktor psikologi meliputi motivasi , persepsi dan sikap konsumen. Dimana faktor ini diyakini sebagai penentu utama dalam pengambilan keputusan. Hasil penelitian menunjukkan bahwa motivasi, persepsi dan sikap konsumen berpengaruh signifikan terhadap keputusan pembelian.

\section{Kerangka Konseptual}

Berdasarkan landasan teori dan penelitian terdahulu, maka dapat disusun kerangka konseptual penelitian sebagai berikut :

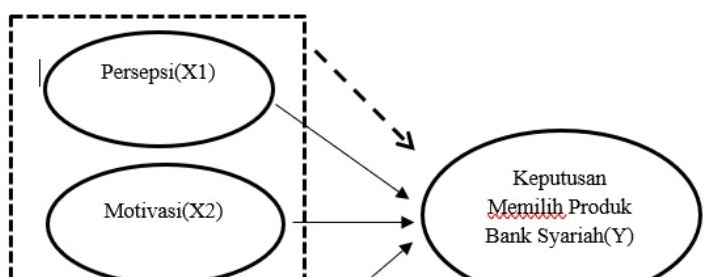

\section{Gambar 1. Kerangka Konseptual}

\section{Hipotesis Penelitian}

Berdasarkan kerangka konseptual tersebut maka dapat disusun hipotesis penelitian sebagai berikut :

1. Persepsi, Motivasi dan Pengetahuan berpengaruh signifikan secara simultan terhadap keputusan masyarakat memilih bank syariah

2. Persepsi berpengaruh signifikan terhadap keputusan masyarakat memilih bank syariah.

3. Motivasi berpengaruh signifikan terhadap keputusan masyarakat memilih bank syariah.

4. Pengetahuan berpengaruh signifikan terhadap keputusan masyarakat memilih bank syariah. 


\section{Metode Penelitian}

Penelitian ini merupakan penelitian yang menggunakan data primer dengan etode survei. Instrumen penelitian diperoleh dengan cara pengumpulan data primer dengan menyebarkan kuesioner kepada para responden. Penelitian dilakukan di Banjarmasin terhadap nasabah bank syariah.

Populasi adalah seluruh masyarakat yang menjadi nasabah Bank Syariah. Dalam penelitian ini jumlah populasi adalah seluruh masyarakat yang menjadi nasabah Bank Syariah. Jumlah sampel mengacu pada pendapat Roscoe dalam Sugioyono (2008:129) yaitu 10 kali dari jumlah variabel yang diteliti. Sampel penelitian adalah 100 responden. Dalam menentukan jumlah sampel menggunakan metode nonprobability sampling dengan teknik accidental sampling.

Variabel terdiri dari variabel dependen dan variabel independen sebagai berikut :

1. Variabel Dependen

Variabel dependen adalah variabel yang menjadi pusat perhatian peneliti (Ferdinand, 2006). Variabel dependen yaitu variabel yang nilainya dipengaruhi oleh variabel independen. Yang dijadikan sebagai variabel dependen dalam penelitian ini adalah keputusan masyarakat memilih produk bank syariah (Y).

2. Variabel Independen Variabel independen adalah variabel yang mempengaruhi variabel dependen, baik yang pengaruhnya positif maupun yang pengaruhnya negatif (Ferdinand, 2006). Variabel independen dalam penelitian ini adalah :
a. Persepsi (X1)
b. Motivasi (X2)
c. Pengetahuan (X3)

\section{Hasil dan Pembahasan Uji Validitas dan Reliabilitas}

Uji Validitas dan Reliabilitas instrumen penelitian dilakukan menggunakan program SPSS for windows release 22. Hasil uji Validitas dan Reliabilitas disajikan pada Tabel berikut.

Tabel 2. Hasil Uji

\begin{tabular}{|c|c|c|c|}
\hline \multirow[b]{2}{*}{ Variabel } & \multirow[b]{2}{*}{ Item } & \multicolumn{2}{|c|}{ Uji Validitas } \\
\hline & & $\begin{array}{c}\text { Nilai } \mathbf{r} \\
\text { hasil }\end{array}$ & Ket \\
\hline \multirow{4}{*}{$\begin{array}{c}\mathrm{X} 1 \\
\text { Persepsi }\end{array}$} & $\mathrm{X} 1$ & 0,839 & Valid \\
\hline & $\mathrm{X} 2$ & 0,932 & Valid \\
\hline & X3 & 0,886 & Valid \\
\hline & $\mathrm{X} 4$ & 0,913 & Valid \\
\hline \multirow{5}{*}{$\begin{array}{c}\mathrm{X} 2 \\
\text { Motivasi }\end{array}$} & $\mathrm{X} 5$ & 0,836 & \multirow{5}{*}{$\begin{array}{l}\text { Valid } \\
\text { Valid } \\
\text { Valid } \\
\text { Valid }\end{array}$} \\
\hline & X6 & 0,909 & \\
\hline & $\mathrm{X} 7$ & 0,909 & \\
\hline & X8 & 0,909 & \\
\hline & X9 & 0,886 & \\
\hline \multirow{6}{*}{$\begin{array}{c}\mathrm{X} 3 \\
\text { Pengetahuan }\end{array}$} & $\mathrm{X} 10$ & 0,563 & \multirow{6}{*}{$\begin{array}{l}\text { Valid } \\
\text { Valid } \\
\text { Valid } \\
\text { Valid } \\
\text { Valid }\end{array}$} \\
\hline & $\mathrm{X} 11$ & 0,325 & \\
\hline & $\mathrm{X} 12$ & 0,463 & \\
\hline & $\mathrm{X} 13$ & 0,693 & \\
\hline & X14 & 0,733 & \\
\hline & $\mathrm{X} 15$ & 0,696 & \\
\hline $\mathrm{Y}$ & Y1 & 0,897 & Valid \\
\hline \multirow{4}{*}{$\begin{array}{c}\text { Keputusan } \\
\text { memilih } \\
\text { Bank } \\
\text { Svariah }\end{array}$} & $\mathrm{Y} 2$ & 0,926 & Valid \\
\hline & $\mathrm{Y} 3$ & 0,916 & Valid \\
\hline & Y4 & 0,908 & Valid \\
\hline & Y5 & 0,928 & Valid \\
\hline
\end{tabular}

Sumber : Data Primer Diolah

Berdasarkan Tabel 2 di atas, Secara keseluruhan instrumen dari variabel penelitian valid karena memiliki nilai koefesien korelasi $r>0,3$. 
Tabel 3. Uji Reliabilias

\begin{tabular}{|l|l|l|}
\hline \multirow{2}{*}{ Variabel } & \multicolumn{2}{c|}{ UJi Reliabilitas } \\
\cline { 2 - 3 } & $\begin{array}{c}\text { Nilai } \\
\text { Alpha }\end{array}$ & Keterangan \\
\hline $\begin{array}{l}\text { X1 } \\
\text { Persepsi }\end{array}$ & 0,911 & Reliabel \\
\hline $\begin{array}{l}\text { X2 } \\
\text { Motivasi }\end{array}$ & 0,933 & Reliabel \\
\hline $\begin{array}{l}\text { X3 } \\
\text { Pengetahuan }\end{array}$ & 0,624 & Reliabel \\
\hline $\begin{array}{l}\text { Y } \\
\text { Keputusan memilih } \\
\text { Bank syariah }\end{array}$ & 0,951 & Reliabel \\
\hline
\end{tabular}

Sumber : Data Primer Diolah

Berdasarkan tabel 3, Seluruh nilai alpha lebih besar dari 0,6, sehingga dapat disimpulkan semua instrumen dalam penelitian ini adalah reliabel.

\section{Analisis Regresi Linear Berganda}

Analisis regresi dalam penelitian ini menggunakan program SPSS for window release 2 , seperti terlihat pada tabel di bawah ini.

Tabel 4. Uji Regresi Berganda

\begin{tabular}{|c|c|c|c|c|c|}
\hline \multirow[b]{2}{*}{ Model } & \multicolumn{2}{|c|}{$\begin{array}{l}\text { Unstandardize } \\
\text { d Coefficients }\end{array}$} & $\begin{array}{c}\text { Standardize } \\
\mathrm{d} \\
\text { Coefficient } \\
\mathrm{s}\end{array}$ & \multirow[b]{2}{*}{$\mathrm{t}$} & \multirow[b]{2}{*}{ Sig } \\
\hline & B & $\begin{array}{l}\text { Std. } \\
\text { Error }\end{array}$ & Beta & & \\
\hline 1 (Constant) & $\begin{array}{r}12,56 \\
5\end{array}$ & 3,158 & & $\begin{array}{r}3,97 \\
8\end{array}$ & $\begin{array}{r}, 00 \\
0\end{array}$ \\
\hline Persepsi & ,363 & , 145 & ,269 & $\begin{array}{r}2,50 \\
5\end{array}$ & $\begin{array}{r}, 01 \\
4\end{array}$ \\
\hline Motivasi & ,586 & ,094 & ,570 & $\begin{array}{r}6,23 \\
7\end{array}$ & $\begin{array}{r}, 00 \\
0\end{array}$ \\
\hline $\begin{array}{l}\text { Pengetahua } \\
\mathrm{n}\end{array}$ &,- 376 & 137 &,- 246 & $\begin{array}{r}- \\
2,74 \\
0\end{array}$ & $\begin{array}{r}, 00 \\
7\end{array}$ \\
\hline
\end{tabular}

a. Dependent Variable: Keputusan Memilih

Berdasarkan Tabel 4 di atas, dapat ditulis persamaan model regresi sebagai berikut:

$$
\begin{aligned}
Y= & 12,565+0,363(X 1)+0,586(X 2)- \\
& 0,376(X 3)
\end{aligned}
$$

Tabel 5. R Square

Model Summary ${ }^{b}$

\begin{tabular}{|l|r|r|r|r|}
\hline Model & \multicolumn{1}{|c|}{$\mathrm{R}$} & $\begin{array}{c}\mathrm{R} \\
\text { Square }\end{array}$ & $\begin{array}{c}\text { Adjusted R } \\
\text { Square }\end{array}$ & $\begin{array}{c}\text { Std. Error } \\
\text { of the } \\
\text { Estimate }\end{array}$ \\
\hline 1 &, $699^{\mathrm{a}}$ &, 488 &, 472 & 1,6993 \\
\hline
\end{tabular}

a. Predictors: (Constant), Pengetahuan, Motivasi, Persepsi

b. Dependent Variable: Keputusan Memilih

Berdasarkan hasil perhitungan tabel 5, besarnya koefesien korelasi berganda $\left(\mathrm{R}^{2}\right)$ sebesar 0,488 . Hal ini berarti $48,80 \%$ variasi Keputusan Memilih Produk Bank Syariah dapat dijelaskan oleh variabel Persepsi, Motivasi dan Pengetahuan. Sedangkan sisanya 51,20\% dijelaskan oleh sebab-sebab lain diluar model.

\section{Uji Hipotesis}

\section{Uji Secara Simultan(Uji Statistik F)}

\section{Tabel 6. Uji Simultan}

ANOVA ${ }^{\mathrm{a}}$

\begin{tabular}{|l|r|c|c|c|c|}
\hline Model & $\begin{array}{r}\text { Sum of } \\
\text { Squares }\end{array}$ & df & $\begin{array}{c}\text { Mean } \\
\text { Squar } \\
\mathrm{e}\end{array}$ & $\mathrm{F}$ & Sig. \\
\hline $\begin{array}{l}1 \text { Regressio } \\
\mathrm{n}\end{array}$ & 264,18 & 3 & 88,063 & 30,49 &, 000 \\
& 9 & 8 & $\mathrm{~b}$ \\
Residual & 277,20 & 9 & 2,888 & & \\
1 & 6 & & & \\
Total & 541,39 & 9 & & & \\
0 & 9 & & & \\
\hline
\end{tabular}

\footnotetext{
a. Dependent Variable: Keputusan Memeilih

b. Predictors: (Constant), Pengetahuan, Motivasi,

Persepsi
} 
Berdasarkan uji ANOVA atau F test didapat $\mathrm{F}$ hitung sebesar 30,498 dengan probabilitas signifikansi 0.000 . Sehingga hipotesis ini diterima karena probabilitas signifikansi jauh lebih kecil dari 0.05, maka dapat dikatakan bahwa Persepsi, Motivasi dan Pengetahuan secara bersamasama berpengaruh signifikan terhadap keputusan memilih produk bank syariah.

\section{Uji Secara parsial}

Hipotesis pertama menyatakan bahwa Persepsi berpengaruh signifikan terhadap keputusan memilih produk bank syariah. Terbukti hipotesis ini diterima karena probabilitas signifikansi $<0,05$ yaitu 0.014 . Hal ini berarti bahwa variabel Persepsi berpengaruh signifikan terhadap keputusan memilih produk bank syariah.

Hipotesis kedua menyatakan bahwa Motivasi berpengaruh signifikan terhadap keputusan memilih produk bank syariah. Terbukti hipotesis ini diterima karena probabilitas signifikansi $<0,05$ yaitu 0.00 . Hal ini berarti bahwa variabel Motivasi berpengaruh signifikan terhadap keputusan memilih produk bank syariah.

Hipotesis ketiga menyatakan bahwa Pengetahuan berpengaruh signifikan terhadap keputusan memilih produk bank syariah. Terbukti hipotesis ini diterima karena probabilitas signifikansi $<0,05$ yaitu 0.007 . Hal ini berarti bahwa variabel Pengetahuan berpengaruh signifikan terhadap keputusan memilih produk bank syariah.

\section{Kesimpulan}

Berdasarkan hasil penelitian, maka dapat disimpulkan bahwa :

1.Variabel Persepsi, Motivasi dan Pengetahuan secara simultan berpengaruh signifikan terhadap keputusan memilih produk bank syariah.

2. Variabel Persepsi, Motivasi dan Pengetahuan secara parsial berpengaruh signifikan terhadap keputusan memilih produk bank syariah.

3. Dari ketiga variabel tersebut Motivasi mempunyai pengaruh yang paling dominan terhadap keputusan masyarakat memilih produk bank syariah.

\section{Saran}

Berdasarkan hasil penelitian, maka saran dalam penelitian ini adalah sebagai berikut:

1. Perusahaan harus terus meningkatkan Persepsi, Motivasi dan Pengetahuan masyarakat terhadap produk bank syariah karena ketiga variabel tersebut berpengaruh signifikan terhadap keputusan masyarakat memilih produk bank syariah.

Persepsi masyarakat terhadap bank syariah harus terus ditingkatkan dengan cara : perusahaan terus meningkatkan kinerja pelayanannya melalui sdm yang berkualitas dan profesional, penggunaan teknologi canggih dalam mendukung pelayanannya, serta dalam operasinya harus konsisten dan dapat benar - benar menjamin nasabah dilayani dengan prinsif - prinsif syariat islam sehingga masyarakat yakin dan percaya bahwa bank syariah adalah bank islami.

Pengetahuan masyarakat akan bank syariah dan produknya harus terus ditingkatkan melalui promosi dan iklan yang lebih gencar baik media cetak maupun elektronik, memperbanyak melakukan event - event yang disponsori bank syariah, melakukan kerjasama dengan dunia pendidikan melakukan seminar - seminar dengan topik ekonomi syariah dan produk perbankan syariah serta melakukan kerjasama yang intensif dengan pemerintah dalam upaya mendukung dan memperkenalkan bank syariah kepada masyarakat. Dengan demikian masyarakat akan lebih familiar dan dekat dengan bank syariah dan produk layanannya.

Variabel Motivasi merupakan faktor yang berpengaruh dominan terhadap keputusan masyarakat memilih produk bank syariah, oleh karena itu variabel ini harus terus jadi perhatian utama perusahaan, dengan cara selalu memberikan pelayanan terbaik dan berupaya terus untuk memperbaiki pelayanan, inovasi produk, menjamin keamanan transaksi dan bisnis yang 
dilakukan selalu berpedoman pada prinsifprinsif syariat islam, serta memberikan bonus dan nisbah bagi hasil yang kompetitif dan menguntungkan bagi nasabah.

2. Bagi peneliti berikutnya yang mengangkat masalah yang sama hendaknya mempertimbangkan variabel lainya di luar model ini, karena variabel pada penelitiannya memiliki hubungan yang tidak terlalu kuat dalam menjelaskan faktor yang mempengaruhi masyarakat memilih produk bank syariah.

\section{Daftar Pustaka}

Alsadek H. Gait and Andrew C. Worthington, 2009, Attitudes, Perceptions and Motivations of Libyan Retail Consumers toward Islamic Methods of Finance, Asian Finance Association 2009 International Conference, Brisbane, 30 June-3 July, 2009. Griffith Business School, Griffith University.

Ajzen, I. (2005). Attitudes, Personality and Behavior. New York: Open University Press-Mc Graw- Hill Education.

Asri, Faradilla Novita, 2017, Skripsi, Analisis Faktor Pertimbangan Dan Pengetahuan Masyarakat Surakarta Terhadap Minat Menabung Di Bank Syari'Ah Mandiri Surakarta.

Basu Swastha Dharmmesta, T. Hani Handoko, 2000, Manajemen Pemasaran" Analisa perilaku konsumen ". Edisi pertama cetakan ketiga.BPFE-Yogyakarta, Yogyakarta

Engel, James F, Roger D Blackwell, dan Paul Miniard, 1995, Consumer Behavior, Eigth Edition The Dryden Press : Forth Worth.
Ergun, U., \& Djedovic, I. (2010). Islamic Banking with a Closer Look at Bosnia and Herzegovina: Knowledge , Perceptions and Decisive Factors for Choosing Islamic Banking. 8th International Conference on Islamic Economics and Finance Islamic, 1-12.

Ferdinand, Augusty, 2006, Metode Penelitian Manajemen, Semarang : Badan Penerbit Universitas Diponegoro.

Ghozali, Imam, 2005, Aplikasi Multivariate Dengan Program SPSS, Badan Penerbit Diponegoro.

Haryadi, 2007, Persepsi Masyarakat Terhadap Perbankan Syariah, Jurnal Bisnis \& Manajemen Volume 7 N0 22007.

Hawkins, D. I., \& Mothersbaugh, D. L. (2013). Consumer Behavior Building Marketing Strategy (Vol. XII). McGraw-Hill.

Kotler, Philip, dan Gary Amstrong, 2001, Dasar-dasar Pemasaran, Jilid Satu, Edisi Kesembilan, Penerbit PT. Gramedia Pustaka Utama : Jakarta

Philip, Manajemen Pemasaran : Analisis Implementasi dan Kontrol, Jilid Satu Penerbit : Prenhalindo Jakarta.

Philip, Marketing Management, Nineth Edition Prantice Hall : New Jersey

Malhotra, Nares K.2002. Marketing research. Edisi Keempat. Uper Saddle River, New Jersey : PrenticeHall Inc.

Muhammad, 2005, Manajemen Bank Syariah. Yogyakarta: Yogyakarta. 
Mowen. H. 2002. Perilaku Konsumen. Jilid I.

Penerbit. Andi. Yogyakarta.

Robbin, Stephen, 2008, dan Judge, Timothy A, Perilaku Organisasi, Edisi 12, Penerbit Salemba Empat.

Sasangka, Ari Luhur, 2010, Analisis FaktorFaktor yang Mempengaruhi Keputusan Konsumen dalam Pembelian Minuman Energi.

Schiffman, Leon G, dan Leslie Lazar Kanuk, 1994, Consumer Behaviour, Fifth Editions, Prantice-Hall Inc : New Jersey

Schiffman, L. G., \& Wisenblit, J. (2015). Consumer Behavior (Vol. XI). England: Pearson Education Limited.

Sekaran, Umar, 2006, Metode Penelitian untuk Bisnis, Edisi Empat, Penerbit Salemba Empat

Setiadi, N. (2013). Perilaku Konsumen : Perspektif Kontemporer Pada Motif, Tujuan, dan Keinginan Konsumen (Vol. V). Jakarta: Kencanca Prenada Media Group.

Sudarsono, Heri. Bank dan Lembaga Keuangan Syariah(Deskripsi danIlustrasi).Yogyakarta: 2003.

Sugiyono, 2008, Metode Penelitian Bisnis, Cetakan Keduabelas, Penerbit Alfabeta Bandung.

Undang - Undang No. 21 Tahun 2008 Tentang Perbankan syariah.

Walgito, Bimo. (2004). Pengantar Psikologi Umum. Penerbit Andi, Yogyakarta. 